Psychological Topics, 27 (2018), 1, 73-89

Original Scientific Paper - UDC - 616.34-002

159.9.072

\title{
Correlates of Body Mass Index in Moderate to Severe Irritable Bowel Syndrome Patients
}

\author{
Abbey C. Braun, Brian M. Quigley, Rebecca Firth, Gregory D. Gudleski, and \\ Jeffrey M. Lackner on behalf of the IBSOS Research Group \\ University at Buffalo, Jacobs School of Medicine, Division of Gastroenterology, \\ Department of Medicine, Buffalo, NY, USA
}

\begin{abstract}
Irritable bowel syndrome (IBS) is a common and potentially disabling gastrointestinal (GI) disorder that is subject to strong psychological influences particularly among more severe IBS patients. Little is known about the role of actionable lifestyle factors (e.g., obesity) that influence the trajectory of other chronic diseases. This study examined the associations between obesity and different aspects of illness experience among more severe IBS patients. We hypothesized that Body Mass Index (BMI) would positively correlate with worse health outcomes including more severe IBS symptoms, extraintestinal complaints, and emotional distress. At pretreatment baseline in a National Institutes of Health (NIH)-funded behavioral trial, 448 Rome-diagnosed IBS patients $\left(M_{A G E}=41 ; M_{B M I}=26\right.$, Female $=8 \%$ ) were administered a test battery that included a variety of clinical (IBS symptom severity, fear of GI symptoms, BMI, etc.), and sociodemographic (e.g. age, etc.) variables. BMI was positively and significantly correlated with somatization (unexplained somatic complaints) but not IBS symptom severity or emotional distress. A series of moderated multiple regression analyses showed that the associations between BMI and somatization were moderated by the interaction between BMI and age, and fear of GI symptoms. Older patients with higher BMI reported higher levels of somatization and patients who were more fearful of GI symptoms were more likely to experience somatization if they also had a high BMI. These data highlight the relationship between lifestyle factors and extraintestinal symptoms among more severe IBS patients and the impact of both sociodemographic (age) and psychosocial (fear of GI symptoms) factors on this relationship.
\end{abstract}

Keywords: irritable bowel syndrome, gastrointestinal disorder, body mass index, visceral sensitivity, somatization

$\square$ Jeffrey M. Lackner, Behavioral Medicine Clinic, Department of Medicine, University at Buffalo, ECMC 462 Grider Street, Buffalo, NY 14215, USA. E-mail: lackner@ buffalo.edu

Research reported in this manuscript was supported by the NIH/NIDDK Grant 77738 (Dr. Lackner). The content is solely the responsibility of the authors and does not necessarily represent the official views of NIH.

We thank members of the IBSOS Research Group (Darren Brenner, Ann Marie Carosella, Jim Jaccard, Leonard Katz, Laurie Keefer, Susan Krasner, Chang-Xing Ma, Christopher Radziwon, Michael Sitrin) for their assistance on various aspects of the research reported in this manuscript. 


\section{Introduction}

Irritable bowel syndrome (IBS) is a chronic, oftentimes disabling gastrointestinal (GI) disorder characterized by abdominal pain associated with diarrhea and/or constipation. With a worldwide prevalence of $11 \%$ (Lovell \& Ford, 2012), IBS is the most common GI disorder seen by gastroenterologists and primary care physicians. The painful, unpredictable, and uncontrollable nature of IBS symptoms is a source of quality of life impairment comparable to life-threatening conditions such as diabetes mellitus and hepatitis (Enck et al., 2016). Beyond its personal toll, IBS exacts substantial economic costs, estimated at \$US28 billion annually (Everhart \& Ruhl, 2009).

The illness burden of IBS is complicated by the absence of a reliable biomarker. For this reason, IBS is best understood as a biopsychosocial problem that involves the interplay of physiological, environmental, and psychological factors (Mayer, Labus, Tillisch, Cole, \& Baldi, 2015). Psychological factors are believed to have a particularly strong impact on the health status of more severe IBS patients (van Tilburg, Palsson, \& Whitehead, 2013). Research supporting the relationship between psychosocial processes and IBS have generally focused on negative aspects of patients' illness experience such as emotional distress, maladaptive coping, faulty threat appraisal, inadequate support systems, and childhood adversity. Much less research has focused on the role of lifestyle factors such as eating patterns, tobacco or alcohol use, sleep, and physical activity. These factors are important because they are actionable and have an established impact on the trajectory of chronic disease (Fortin et al., 2014).

The purpose of this study was to assess the relationship between obesity and clinical aspects of illness experience of IBS patients. Physiologically, obesity is associated with alterations in GI motility (Xing \& Chen, 2004), which is regarded as an important influence of symptom pathogenesis in IBS (Quigley, 2003). Motility refers to the rhythmic muscular contractions that propel ingested food from the mouth through the digestive tract (Chang \& Leung, 2014). Motility disturbances have been described throughout the GI tract of IBS patients and have been hypothesized as a cause of alterations in bowel transit time (i.e., the interval between consumption of food and its elimination as feces) and defecatory symptoms such as constipation or diarrhea (Accarino, Azpiroz, \& Malagelada, 1995). Patients with diarrhea-predominant IBS have an increased number of fast colonic contractions, whereas patients with constipation-predominant IBS have fewer high-amplitude propagated colonic contractions (Bazzocchi et al., 1990). Secondly, obesity may be understood as a chronic stressor that is manifested in dysregulation of the hypothalamic-pituitary-adrenal (HPA) axis and sympathetic nervous system (SNS). These systems, which together compose the two major branches of the central stress response system, can modulate mucosal immune function (Chang et al., 2009). An imbalance in these systems has been reported in stress-sensitive disorders like IBS (Dinan et al., 2006). Moreover, an imbalance in these systems can predispose some 
individuals to negative mood states, such as depression and anxiety, which can aggravate IBS symptoms and other co-occurring somatic complaints. Psychologically, a significant proportion of obese patients experience heightened levels of stress (Scott, Melhorn, \& Sakai, 2012). Chronic life stress is known to potentiate a greater preference for highly palatable energy and nutrient-dense "comfort" foods, namely those that are high in sugar and fat (Chandler-Laney et al., 2007; Dallman et al., 2003). While these foods may, in the short-term, modulate negative emotions arising from stressful live events, they may in the longer term trigger IBS symptoms (Hayes, Fraher, \& Quigley, 2014). Thus, the patient lacking adequate coping resources is caught between the desire to reduce unpleasant emotional and somatic sensations. Further, chronic social stress arising from poor interpersonal relationships has been identified as an environmental factor that may contribute to the development of obesity (Scott et al., 2012) and IBS (Lackner \& Gurtman, 2004).

Drawing from these data, we expected that more obese IBS patients, based on baseline BMI, would report worse health outcomes including more severe IBS symptoms, comorbid somatic complaints including somatization (the presentation of medically unexplained somatic complaints), and greater emotional distress. A secondary goal was to characterize the relationship between sociodemographic factors and illness experience among more severe IBS patients.

\section{Method}

\section{Participants}

Participants included 448 patients recruited at two tertiary academic medical centers in Buffalo, NY and Chicago, IL, as part of a National Institutes of Health (NIH)-funded clinical trial, the details of which can be found elsewhere (Lackner et al., 2012). Of the 448 individuals in the sample, 358 were female, $90.4 \%$ selfidentified as white, average age was 41.37 years old $(S D=14.80)$, and the average income was $\$ 72$ thousand per year. Participants were enrolled primarily through local media coverage, community advertising, and physician referral. To qualify, participants must have met Rome III IBS diagnostic criteria (Longstreth et al., 2006) without organic gastrointestinal disease as determined by a board-certified study gastroenterologist. Rome criteria define IBS as a recurrent abdominal pain or discomfort at least 3 days per month over the last 3 months that is associated with at least 2 of the following: 1) improvement with defecation, 2) onset associated with a change in stool form, or 3) onset associated with a change in the frequency of stool (Drossman, Corazziari, Talley, Thompson, \& Whitehead, 2000). Because this study was conducted as part of a larger clinical trial of behavioral treatments for moderately to severely affected IBS patients (Lackner et al., 2012), participants must have also reported IBS symptoms of at least moderate intensity (i.e., symptom occurrence at 
least twice weekly for 6 months and causing life interference). Subjects with a presence of comorbid organic GI illness that would adequately explain GI symptoms [i.e., inflammatory bowel disease (IBD) or colon cancer], developmental disability, current or past diagnosis of schizophrenia or other psychotic disorders, current diagnosis of depression with suicidal ideation, and current diagnosis of psychoactive substance abuse were excluded.

\section{Procedure}

After a brief telephone interview to determine whether participants were likely to meet basic inclusion criteria, patients were scheduled for a medical examination to confirm IBS diagnosis (Drossman et al., 2000; Longstreth et al., 2006) and psychometric testing that for the purposes of this study included the test battery described in detail below. Institutional review board approval (University at Buffalo and Northwestern University) and written, signed, informed consent were obtained before study initiation. The study was completed in full compliance with the Declaration of Helsinki.

\section{Measures}

Emotional Distress. The Brief Symptom Inventory (BSI-18; Derogatis, 2000) is an 18-item self-report screening inventory designed to assess respondents' level of psychological distress on three dimensions: somatization, depression, and anxiety. In the current study, only the somatization dimension of the BSI-18 was utilized. Items on this measure ask participants to rate how much they have been distressed or bothered in the past 7 days by the given symptom, using a 5-point Likert scale ranging from 0 (not at all) to 4 (extremely).

IBS Symptom Severity. The Irritable Bowel Syndrome Symptom Severity Scale (IBS-SSS; Francis, Morris, \& Whorwell, 1997) is a 5-item instrument used to measure the severity and frequency of abdominal pain, severity of abdominal distension, dissatisfaction with bowel habits, and interference with quality of life on a 100-point scale. The five items are summed with the total scores ranging from 0 to 500, with higher scores signifying more severe IBS symptoms.

Fear of GI Symptoms. The Visceral Sensitivity Index (VSI; Labus et al., 2004) is a 15-item self-report questionnaire designed to measure those unique aspects of fear, anxiety, and hypervigilance that can accompany misappraisals of visceral sensations and discomfort. Items on the VSI are totaled to yield a range of possible scores from 0 (no fear of GI symptoms) to 75 (strong fear of GI symptoms). This scale has demonstrated reliability and validity in a sample of IBS patients (Lackner et al., 2012).

Body Mass Index (BMI). BMI is the most widely used measurement of obesity and was calculated based on self-reported weight and height $\left(\mathrm{kg} / \mathrm{m}^{2}\right)$ at pre-treatment baseline. 
Sociodemographic Factors. General background information, including patient's age, relationship status, gender, race and ethnicity, education level, income, and employment were obtained at the initial session via an intake questionnaire.

\section{Results}

Characteristics of the sample and correlations between continuous variables are presented in Table 1. Although average BMI in the sample would be classified as overweight, there was a wide range of BMI scores in the sample with the lowest BMI being 16.50 and the highest being 79.30. Similarly, age was also widely dispersed ranging from 41 years of age to 70 .

Before examining our hypotheses in a regression framework, we first examined the univariate correlations between the two outcome measures of interests and the continuous predictor variables of age, BMI, and VSI. As can be seen in Table 1, symptom severity was not significantly correlated with BMI but was correlated with both VSI and with age. Somatization, however, was significantly correlated with BMI and with VSI but not with age.

Table 1

Means, Standard Deviations, and Correlations among Continuous Variables

\begin{tabular}{lrrlllll}
\hline & $M$ & \multicolumn{1}{c}{$S D$} & \multicolumn{1}{c}{1} & 2 & 3 & 4 & 5 \\
\hline 1. Age & 41.37 & 14.80 & - & & & & \\
2. BMI & 26.51 & 6.52 & $.22^{* *}$ & - & & & \\
3. VSI & 44.69 & 13.99 & $-.11^{*}$ & .01 & - & & \\
4. Symptom Severity & 282.54 & 70.97 & $-.10^{*}$ & .01 & $.38^{* *}$ & - & \\
5. Somatization & 4.31 & 4.07 & -.04 & $.17^{* *}$ & $.33^{* *}$ & $.28^{* *}$ & - \\
\hline
\end{tabular}

VSI = Visceral Sensitivity Index; BMI = Body Mass Index; $M=$ Mean; $S D=$ Standard Deviation . ${ }^{*} p<.05 ;{ }^{* *} p<.01$.

\section{Predicting Symptom Severity and Somatization}

In order to examine how age, gender, BMI, and VSI are related to symptom severity and somatization, a series of stepwise moderated multiple regression analyses were conducted. Symptom severity and somatization were examined as the dependent measures in separate regression analyses. In each analysis, age, gender, VSI, and BMI were entered as predictors in the first step and all two-way interactions between those variables were entered in the second step. Because we were interested in how the interaction between BMI and VSI may be moderated by gender and age, we examined the only two three-way interactions in the third step of the equation that would address those questions: the interaction of age by BMI by VSI and the interaction of gender by BMI by VSI. Results of both analyses are presented in Table 2 . 


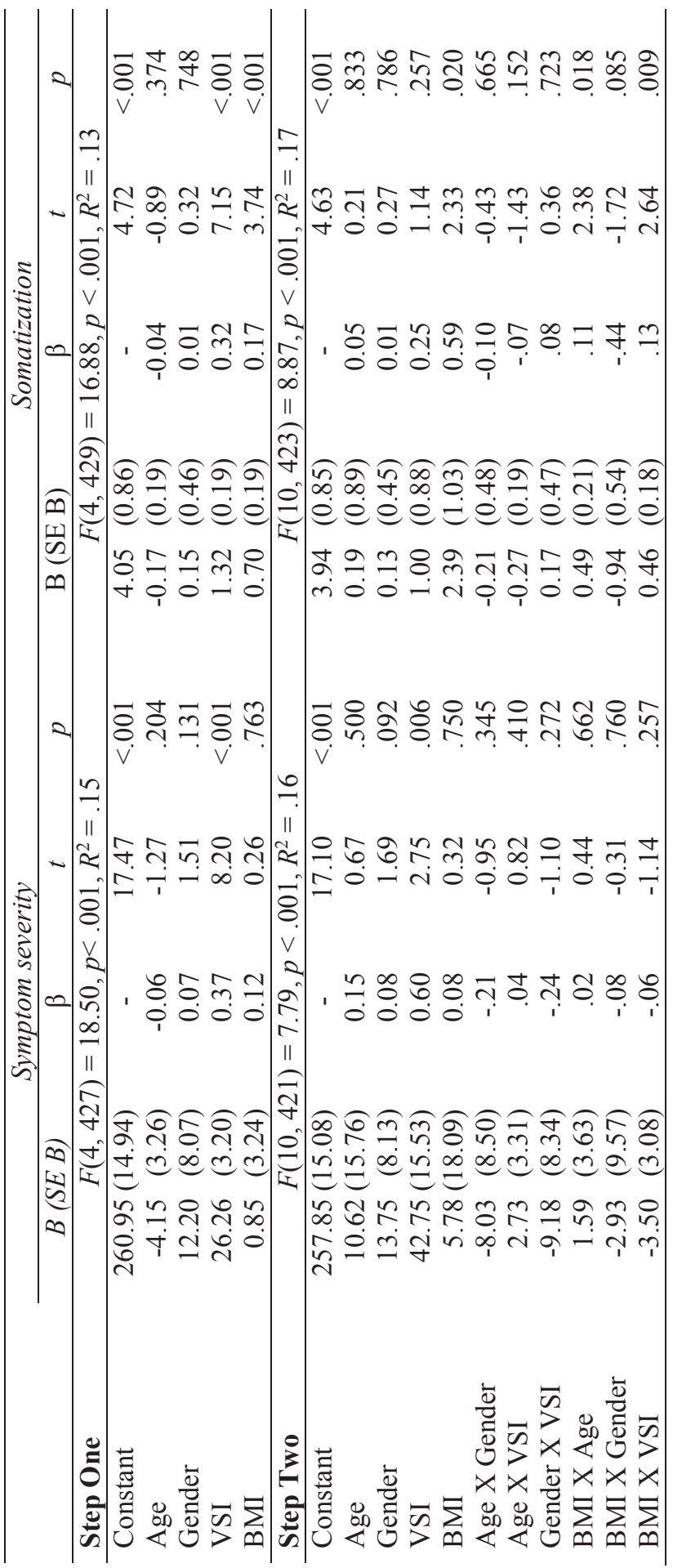


Braun, A. C., Quigley, B., Firth, R., Gudleski, G. D., and Lackner, J. M.:

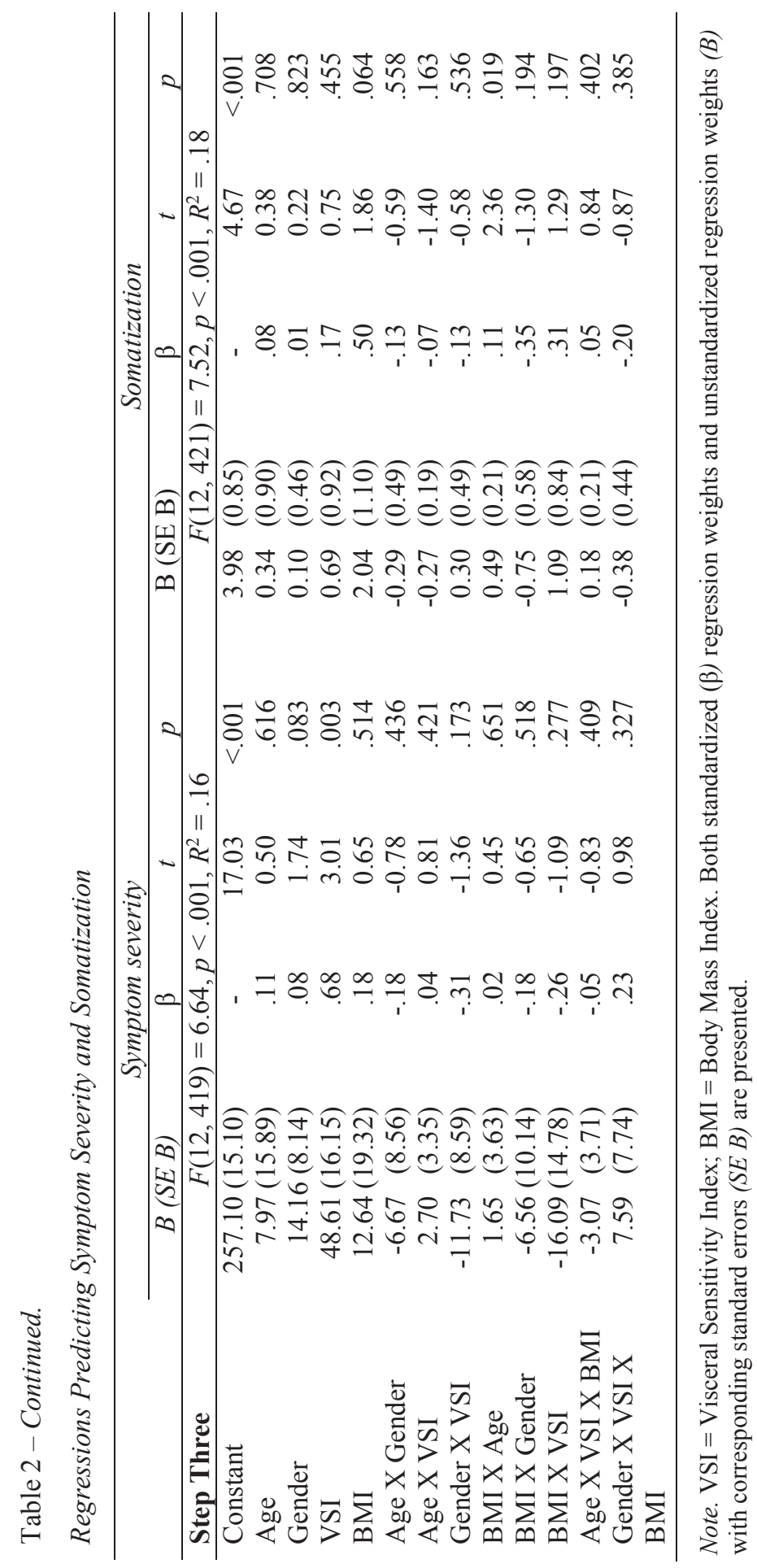




\section{Symptom Severity}

The first step of the multiple regression analysis predicting symptom severity from age, gender, BMI and VSI main effects was significant and accounted for $14 \%$ of the variability in symptom severity. The main effect of VSI was the only significant predictor in the first step of the regression analysis. When all the two-way interactions were entered in the second step, none significantly predicted symptom severity and there was no significant increase in variance accounted for in symptom severity, $\Delta R^{2}=.01, F(6,421)=0.69, p=.652$. When the two three-way interactions of interest were entered in the third step, neither were significant predictors of symptom severity and there was no significant increase in variance accounted for in symptom severity, $\Delta R^{2}=.00, F(2,419)=0.90, p=.419$.

\section{Somatization}

In the first step of the multiple regression analysis examining the main effects model, both BMI and VSI significantly predicted somatization. This model accounted for $13 \%$ of the variance in somatization. In the second step, two interactions significantly predicted somatization and the full model accounted for $17 \%$ of the variance in somatization, a significant increase over the main effects model, $\Delta R^{2}=.04, F(6,423)=3.18, p<.01$. Interactions were deconstructed using the procedures recommended by Aiken and West (1991) to graph the interactions and test the significance of simple slopes. When the interaction between age and BMI was graphed (see Figure 1), the shape of the interaction indicated that somatization was greater in high BMI patients, however, that difference between low and high BMI patients was more pronounced among older patients. The test of the simple slope for the relationship between BMI and somatization among older patients was significant, $\beta=.71, t=2.86, p<.01$, with the greatest levels of somatization being among older patients with the highest BMI scores. However, the relationship of BMI to somatization among younger patients was not significant, $\beta=.47, t=1.75, p=$ .081. The second significant interaction was between BMI and VSI. Graphing this interaction and testing the simple slopes using the same procedures indicted that there was a significant relationship between BMI and somatization for those high on VSI, $\beta=.70, t=2.86, p<.01$, but not among those low on VSI, $\beta=.47, t=1.78, p=$ .076 . While visceral sensitivity also increased somatization, those who were high on visceral sensitivity and high on BMI reported the highest levels of somatization. 


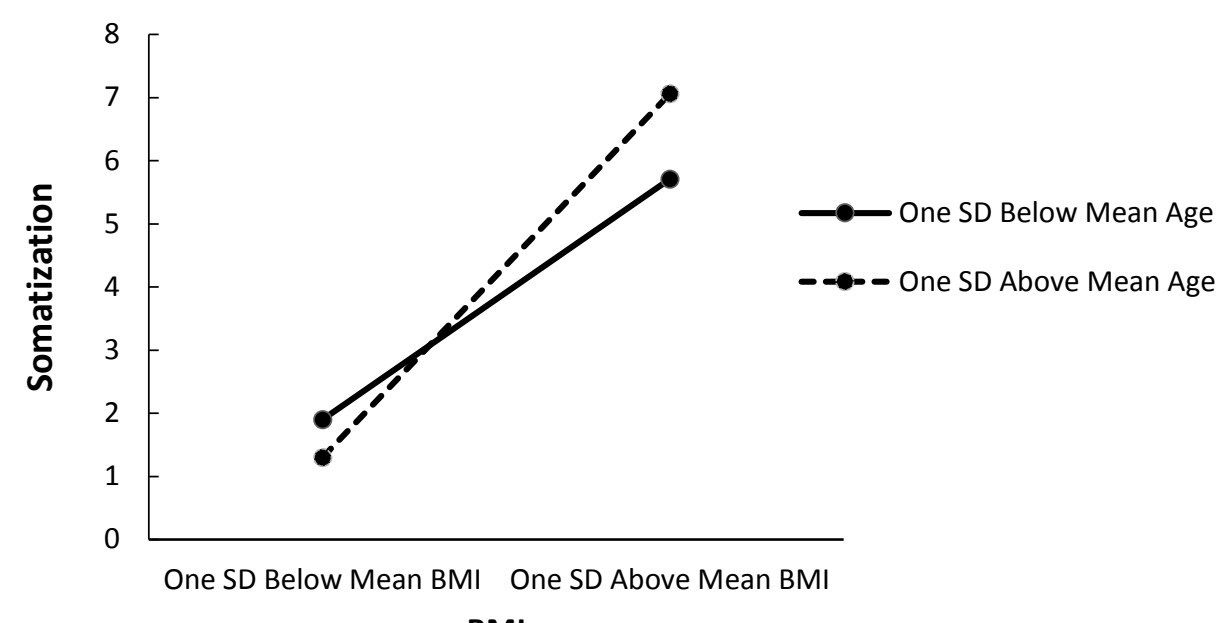

BMI

Figure 1. Interaction between Age and BMI Predicting Somatization. BMI = Body Mass Index.

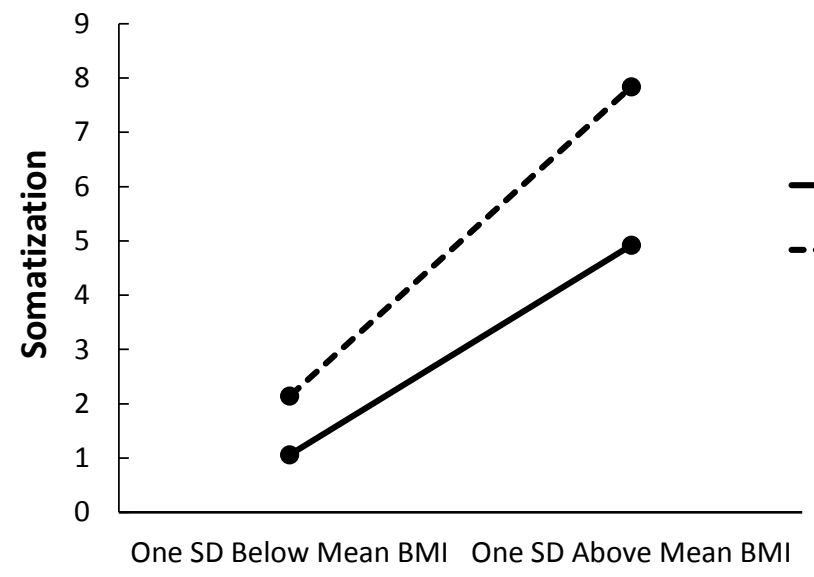

BMI

Figure 2. Interaction between BMI and VSI Predicting Somatization. VSI = Visceral Sensitivity Index; BMI = Body Mass Index.

When the two three-way interactions of interest were entered in the third step, neither were significant predictors of somatization and there was no significant increase in variance accounted for in somatization, $\Delta R^{2}=.01, F(2,421)=0.79, p=$ .453 . 


\section{Discussion}

The purpose of this study was to shed light on the relationship between obesity and health status of more severely affected IBS patients. We hypothesized that IBS patients with higher BMI would report worse health outcomes as evidenced by more severe gastrointestinal symptoms, comorbid extraintestinal complaints, and higher levels of emotional distress. We found mixed support for our hypotheses. The severity of IBS symptoms was significantly related to baseline BMI. Our most robust finding involved the relationship between somatization and both BMI and fear of GI symptoms as measured by the VSI. Somatization refers to medically unexplained bodily symptoms and has been thought to explain the frequent "extra-intestinal" symptoms of IBS (MacLean, Palsson, Turner, \& Whitehead, 2012) and the high cooccurrence between functional gastrointestinal disorders (FGIDs) and other functional somatic syndromes that are similarly defined by unexplained bodily symptoms (Whitehead et al., 2007). In research with another FGID, functional dyspepsia (FD), somatization has also been shown to be associated with GI sensorimotor processes including gastric sensitivity and gastric emptying as well as with impaired quality of life (Van Oudenhove et al., 2011) symptom severity and weight loss across the spectrum of functional gastroduodenal disorders (Clauwaert, 2012), and may be a "risk factor" for the development of FD (Gathaiya, 2009). Higher levels of somatization correspond with heath care use and quality of life impairment (Spiegel, Kanwal, Naliboff, \& Mayer, 2005) and predict a poor response to treatment (Porcelli, Fabbri, \& Serretti, 2012), including increasing one's likelihood of discontinuing medication due to perceived adverse effects (Agosti, Quitkin, Stewart, \& McGrath, 2002). In the case of our study, individuals with higher somatization levels reported stronger fears of GI symptoms. These data build on recently published research by Fergus, Limbers, Griggs, \& Kelley (2018) who found that somatic complaints in a sample of obese patients was predicted by a set of factors including anxiety sensitivity (AS), which is conceptually and empirically related to visceral sensitivity (VS). Whereas AS taps into fear of arousal symptoms, VS measures fear of GI symptoms. Our data extend the work by Fergus et al. (2018) by examining the role of age and gender as well as the interactions between BMI and VS. Further research is needed to tease out the causal relationship between fear of GI symptoms, somatic complaints, and their underlying mediators (e.g., autonomic arousal, cognitive bias, etc.).

To our knowledge, no prior research has linked VSI to BMI in IBS patients, although Hearon, Utschig, Smits, Moshier, and Otto (2013) has found that overweight/obese individuals reported significantly higher anxiety sensitivity (AS) than normal weight participants. The VSI is descriptively similar to the Anxiety Sensitivity Index (ASI) and data implicating AS as a potential risk factor for maladaptive eating behavior may be instructive for making sense of our findings. AS is a dispositional cognitive characteristic reflecting a tendency to fear anxiety and arousal-related symptoms (e.g., chest pain, racing heart, breathlessness) based on the 
belief that they have catastrophic physical, mental, or social consequences (McNally, 2002). The VSI has a more narrow focus denoting a tendency to fear GI symptoms. Individuals with high AS have a tendency to experience heightened levels of negative affect and a propensity to respond more strongly to negative emotions than their low AS counterparts (Otto, Pollack, Fava, Uccello, \& Rosenbaum, 1995). Lacking an effective set of emotion regulation skills, high AS individuals tend to adopt more maladaptive coping strategies to modulate negative affect. These strategies can include emotional eating (eating to modulate negative affect) and avoidance or premature discontinuation of physical activities, particularly those that elicit some somatic discomfort (Hearon, Quatromoni, Mascoop, \& Otto, 2014; Smits, Tart, Presnell, Rosenfield, \& Otto, 2010). It is possible that VS governs eating behaviors and physical activity of IBS patients in much the same way that AS does. If so, heightened fear of GI symptoms may draw IBS patients into a vicious cycle that restricts them to sedentary indoor activities that affords them fewer opportunities for energy expenditure and more for energy intake. This formulation echoes reports of IBS patients who complain of engaging in fewer recreational activities due to fear of negative consequences (e.g., having an accident while exercising or lack of availability of a bathroom). Clinically, these data suggest possible avenues for improving the health and wellbeing of IBS patients through lifestyle interventions such as exercise. If fear of GI symptoms interferes with IBS patients' ability to engage in regular or sustained activity, then more robust treatments may depend on targeting these fears and resultant exercise avoidance through cognitive behavioral technique strategies. These strategies may include interoceptive exposure that emphasize habituation to threat related cues (Ljotsson et al., 2011).

The relationship between BMI and somatization is complex on the basis of our data. As noted above, patients with higher BMIs reported higher levels of somatization. However, the difference between low and high BMI patients was more pronounced among older participants. That is, we found higher levels of somatization among older IBS patients with the highest BMI scores. Traditionally, somatization among the elderly has been viewed as a form of masked depression (Sheehan \& Banerjee, 1999). The interaction between age and BMI suggests that the relationship may not necessarily be a physical manifestation of psychiatric conditions but rather reflective of broader health problems that often afflict many older adults. As their health deteriorates and physical activity declines, elderly individuals may be forced to make lifestyle changes that sets the stage for increased somatic complaints. Warwick \& Salkovskis (1990) have developed a cognitive behavioral model of somatization that emphasizes cognitive processes including selective attention to bodily sensations, catastrophic interpretation of benign symptoms, and reliance on avoidance behaviors (e.g., reassurance-seeking) to cope with medically unexplained symptoms. These factors interact and fuel one another in a reciprocal manner. Their impact may be intensified by aspects of aging such as frailty, reduced social support that would otherwise buffer them from pathogenic effects of stress (Cohen \& Wills, 
1985), compromised physical functioning, and an increased sense of vulnerability in the face of worsening health (Charles \& Carstensen, 2010).

Generally speaking, our data underscore the importance of extraintestinal symptoms as part of the illness experience in more severe IBS patients. Up to twothirds of IBS patients report non-GI symptoms compared to less than $15 \%$ of healthy individuals (Whorwell, McCallum, Creed, \& Roberts, 1986). Some comorbid physical disorders include a cluster of benign medical syndromes such as interstitial cystitis, chronic pelvic pain, migraine and/or tension headaches, and fibromyalgia that are disproportionately associated with IBS (Whitehead et al., 2007). Others include more well-defined physical illnesses such as hypertension and arthritis (Lackner, Gudleski, \& Blanchard, 2004; Whitehead et al., 2007). IBS is associated with significant mental comorbidity as well. In studies (Lackner et al., 2013) that have administered structured clinical interviews to establish the extent of psychiatric comorbidity per criteria as specified in the Diagnostic and Statistical Manual of Mental Disorders (American Psychiatric Association, 1994), approximately 60\% of treatment-seeking IBS patients have a diagnosable psychiatric condition (Blanchard, Keefer, Payne, Turner, \& Galovski, 2002), with generalized anxiety disorder and depression being the most common disorders. By comparison, approximately $25 \%$ of American adults suffer from diagnosable mental disorders (Alegria, Jackson, Kessler, \& Takeuchi, 2003; Kessler et al., 2004). Comorbidity influences illness experience of IBS in a variety of ways. Levy et al. (2001) found that the majority of healthcare charges in patients are for extraintestinal medical conditions. More recently, Lackner et al. (2013) found that medical and psychiatric comorbidity is associated with increased distress, worse physical and mental functioning and quality of life impairment and, for patients with specific clusters of physical and mental conditions (e.g., depression, generalized anxiety disorder, low back pain, insomnia) more severe IBS symptoms. Our data add to this line of research by showing that lifestyle factors (e.g., obesity) and sociodemographic factors (e.g., age) may impact coexisting physical complaints, particularly medically unexplained ones, of IBS patients.

Results should be interpreted in light of study limitations. Because our data are cross-sectional and correlational, we do not intend to suggest that findings demonstrate causal relationships among obesity and IBS-related health outcomes. At best, our data can be construed as suggestive of a possible causal relationship that could be confirmed through future longitudinal analyses. Our data reflected a subset of treatment-seeking individuals who were willing to enroll in a behaviorally-based randomized controlled trial. Therefore, our findings may not necessarily generalize to less psychologically oriented patients or those from primary care settings or community populations (i.e., non-consulters) representative of the majority of individuals with symptoms compatible with IBS. Furthermore, because of the relative demographic homogeneity of our selected sample of patients who were mostly White, female, chronically ill, and educated, our results may not be 
generalizable to a broader, more diverse population. Although our measures satisfy accepted standards for psychometric soundness, data is based on self-report, which means that they are subject to some bias and measurement error. However, we do not believe that our reliance on self-report invalidates our findings. The meaning of our findings could have been increased with the addition of a control group of nonconsulting individuals with IBS symptoms or those with organic GI disease (e.g., IBD). Lastly, because BMI was based on self-report, we may have underestimated actual levels of obesity.

In spite of these imperfections, we believe that these data contribute to what is known about the impact of actionable lifestyle factors on illness experience of IBS patients and ways that may reduce its daily burden.

\section{References}

Accarino, A. M., Azpiroz, F., \& Malagelada, J. R. (1995). Selective dysfunction of mechanosensitive intestinal afferents in irritable bowel syndrome. Gastroenterology, 108(3), 636-643.

Agosti, V., Quitkin, F. M., Stewart, J. W., \& McGrath, P. J. (2002). Somatization as a predictor of medication discontinuation due to adverse events. International Clinical Psychopharmacology, 17(6), 311-314.

Aiken, L. S., \& West, S. G. (1991). Multiple regression: Testing and interpreting interactions. London: Sage.

Alegria, M., Jackson, J. S., Kessler, R. C., \& Takeuchi, D. (2003). National Comorbidity Survey Replication (NCS-R), 2001-2003. Ann Arbor: Inter-university Consortium for Political and Social Research.

American Psychiatric Association (1994). Diagnostic and statistical manual of mental disorders (4th ed.). Washington. D. C.: American Psychiatric Association.

Bazzocchi, G., Ellis, J., Villanueva-Meyer, J., Jing, J., Reddy, S. N., Mena, I., \& Snape, W. J., Jr. (1990). Postprandial colonic transit and motor activity in chronic constipation. Gastroenterology, 98(3), 686-693.

Blanchard, E. B., Keefer, L., Payne, A., Turner, S. M., \& Galovski, T. E. (2002). Early abuse, psychiatric diagnoses and irritable bowel syndrome. Behavioural Research and Therapy, 40(3), 289-298.

Chandler-Laney, P. C., Castaneda, E., Viana, J. B., Oswald, K. D., Maldonado, C. R., \& Boggiano, M. M. (2007). A history of human-like dieting alters serotonergic control of feeding and neurochemical balance in a rat model of binge-eating. International Journal of Eating Disorders, 40(2), 136-142. doi:10.1002/eat.20349

Chang, E. B., \& Leung, P. S. (2014). Gastrointestinal motility. In P. S. Leung (Ed.), The gastrointestinal system: Gastrointestinal, nutritional and hepatobiliary physiology (pp. 35-62). Dordrecht: Springer. 
Chang, L., Sundaresh, S., Elliott, J., Anton, P. A., Baldi, P., Licudine, A., ... Mayer, E. A. (2009). Dysregulation of the hypothalamic-pituitary-adrenal (HPA) axis in irritable bowel syndrome. Neurogastroenterology \& Motilility, 21(2), 149-159. doi:10.1111/j. 1365-2982.2008.01171.x

Charles, S. T., \& Carstensen, L. L. (2010). Social and emotional aging. Annual Review of Psychology, 61, 383-409. doi:10.1146/annurev.psych.093008.100448

Clauwaert, N. (2012). Associations between gastric sensorimotor function, depression, somatization, and symptom-based subgroups in functional gastroduodenal disorders: Are all symptoms equal? Neurogastroenterology \& Motilility, 24, 1088-e565.

Cohen, S., \& Wills, T. A. (1985). Stress, social support, and the buffering hypothesis. Psychological Bulletin, 98(2), 310-357.

Dallman, M. F., Akana, S. F., Laugero, K. D., Gomez, F., Manalo, S., Bell, M. E., \& Bhatnagar, S. (2003). A spoonful of sugar: Feedback signals of energy stores and corticosterone regulate responses to chronic stress. Physiology \& Behavior, 79(1), 3-12.

Derogatis, L. R. (2000). Brief Symptom Inventory-18 (BSI-18): Adminis-tration, scoring, and procedures manual. Minneapolis, MN: National Computer Systems.

Dinan, T. G., Quigley, E. M., Ahmed, S. M., Scully, P., O'Brien, S., O'Mahony, L., ... Keeling, P. W. (2006). Hypothalamic-pituitary-gut axis dysregulation in irritable bowel syndrome: Plasma cytokines as a potential biomarker? Gastroenterology, 130(2), 304311. doi:10.1053/j.gastro.2005.11.033

Drossman, D. A., Corazziari, E., Talley, N. J., Thompson, W. G., \& Whitehead, W. E. (2000). Rome II. The functional gastrointestinal disorders. Diagnosis, pathophysiology and treatment: A multinational consensus (2nd ed.). McLean: Degnon Associates.

Enck, P., Aziz, Q., Barbara, G., Farmer, A. D., Fukudo, S., Mayer, E. A., ... Spiller, R. C. (2016). Irritable bowel syndrome. Nature Reviews Diseases Primers, 2, 16014. doi:10. 1038/nrdp.2016.14

Everhart, J. E., \& Ruhl, C. E. (2009). Burden of digestive diseases in the United States part II: Lower gastrointestinal diseases. Gastroenterology, 136(3), 741-754. doi:10.1053/ j.gastro.2009.01.015

Fergus, T. A., Limbers, C. A., Griggs, J. O., \& Kelley, L. P. (2018). Somatic symptom severity among primary care patients who are obese: Examining the unique contributions of anxiety sensitivity, discomfort intolerance, and health anxiety. Journal of Behavioral Medicine, 41(1), 43-51. doi:10.1007/s10865-017-9873-8

Fortin, M., Haggerty, J., Almirall, J., Bouhali, T., Sasseville, M., \& Lemieux, M. (2014). Lifestyle factors and multimorbidity: A cross sectional study. BMC Public Health, 14, 686. doi:10.1186/1471-2458-14-686

Francis, C. Y., Morris, J., \& Whorwell, P. J. (1997). The irritable bowel severity scoring system: A simple method of monitoring irritable bowel syndrome and its progress. Alimentary Pharmacology \& Therapeutics, 11(2), 395-402.

Gathaiya, N. (2009). Novel associations with dyspepsia: A community-based study of familial aggregation, sleep dysfunction, and somatization. Neurogastroenterology \& Motilility, 21, 922-e69. 
Hayes, P. A., Fraher, M. H., \& Quigley, E. M. (2014). Irritable bowel syndrome: The role of food in pathogenesis and management. Gastroenterology \& Hepatolology, 10(3), 164174.

Hearon, B. A., Quatromoni, P. A., Mascoop, J. L., \& Otto, M. W. (2014). The role of anxiety sensitivity in daily physical activity and eating behavior. Eating Behaviors, 15(2), 255258. doi:https://doi.org/10.1016/j.eatbeh.2014.03.007

Hearon, B. A., Utschig, A. C., Smits, J. A. J., Moshier, S. J., \& Otto, M. W. (2013). The role of anxiety sensitivity and eating expectancy in maladaptive eating behavior. Cognitive Therapy and Research, 37(5), 923-933. doi:10.1007/s10608-012-9491-2

Kessler, R. C., Berglund, P., Chiu, W. T., Demler, O., Heeringa, S., Hiripi, E., ... Zheng, H. (2004). The US National Comorbidity Survey Replication (NCS-R): Design and field procedures. International Journal of Methods in Psychiatric Research, 13(2), 69-92.

Labus, J. S., Bolus, R., Chang, L., Wiklund, I., Naesdal, J., Mayer, E. A., \& Naliboff, B. D. (2004). The Visceral Sensitivity Index: Development and validation of a gastrointestinal symptom-specific anxiety scale. Alimentary Pharmacology \& Therapeutics, 20(1), 8997.

Lackner, J. M., Gudleski, G. D., \& Blanchard, E. B. (2004). Beyond abuse: The association among parenting style, abdominal pain, and somatization in IBS patients. Behaviour Research and Therapy, 42(1), 41-56.

Lackner, J. M., \& Gurtman, M. B. (2004). Pain catastrophizing and interpersonal problems: A circumplex analysis of the communal coping model. Pain, 110(3), 597-604. doi:10.1016/j.pain.2004.04.011

Lackner, J. M., Keefer, L., Jaccard, J., Firth, R., Brenner, D., Bratten, J., ... The IBSOS Research Group. (2012). The Irritable Bowel Syndrome Outcome Study (IBSOS): Rationale and design of a randomized, placebo-controlled trial with 12 month follow up of self- versus clinician-administered CBT for moderate to severe irritable bowel syndrome. Contemporary Clinical Trials, 33(6), 1293-1310. doi:10.1016/ j.cct. 2012. 07.013

Lackner, J. M., Ma, C. X., Keefer, L., Brenner, D. M., Gudleski, G. D., Satchidanand, N., ... Mayer, E. A. (2013). Type, rather than number, of mental and physical comorbidities increases the severity of symptoms in patients with irritable bowel syndrome. Clinical Gastroenterology and Hepatology, 11(9), 1147-1157. doi:10.1016/j.cgh.2013.03.011

Levy, R. L., Von Korff, M. R., Whitehead, W. E., Stang, P., Saunders, K., Jhingran, P., ... Feld, A. D. (2001). Costs of care for irritable bowel syndrome patients in a health maintenance organization. American Journal of Gastroenterology, 96(11), 3122-3129.

Ljotsson, B., Hedman, E., Andersson, E., Hesser, H., Lindfors, P., Hursti, T., ... Andersson, G. (2011). Internet-delivered exposure-based treatment vs. stress management for irritable bowel syndrome: A randomized trial. American Journal of Gastroenterology, 106(8), 1481-1491. doi:10.1038/ajg.2011.139

Longstreth, G. F., Thompson, W. G., Chey, W. D., Houghton, L. A., Mearin, F., \& Spiller, R. C. (2006). Functional bowel disorders. Gastroenterology, 130(5), 1480-1491. 
Lovell, R. M., \& Ford, A. C. (2012). Global prevalence of and risk factors for irritable bowel syndrome: A meta-analysis. Clinical Gastroenterology and Hepatology, 10(7), 712721. doi:10.1016/j.cgh.2012.02.029

MacLean, E. W., Palsson, O. S., Turner, M. J., \& Whitehead, W. E. (2012). Development and validation of new disease-specific measures of somatization and comorbidity in IBS. Journal of Psychosomatic Research, 73(5), 351-355. doi:10.1016/j.jpsychores. 2012. 08.007

Mayer, E. A., Labus, J. S., Tillisch, K., Cole, S. W., \& Baldi, P. (2015). Towards a systems view of IBS. Nature Reviews Gastroenterology \& Hepatology, 12(10), 592-605. doi:10.1038/nrgastro.2015.121

McNally, R. J. (2002). Anxiety sensitivity and panic disorder. Biological Psychiatry, 52(10), 938-946.

Otto, M. W., Pollack, M. H., Fava, M., Uccello, R., \& Rosenbaum, J. F. (1995). Elevated Anxiety Sensitivity Index scores in patients with major depression: Correlates and changes with antidepressant treatment. Journal of Anxiety Disorders, 9(2), 117-123. doi:https://doi.org/10.1016/0887-6185(94)00035-2

Porcelli, S., Fabbri, C., \& Serretti, A. (2012). Meta-analysis of serotonin transporter gene promoter polymorphism (5-HTTLPR) association with antidepressant efficacy. European Neuropsychopharmacology, 22(4), 239-258. doi:10.1016/j.euroneuro. 2011. 10.003

Quigley, E. M. (2003). Current concepts of the irritable bowel syndrome. Scandinavian Journal of Gastroenterology, Suppl(237), 1-8.

Scott, K. A., Melhorn, S. J., \& Sakai, R. R. (2012). Effects of chronic social stress on obesity. Current Obesity Reports, 1(1), 16-25. doi:10.1007/s13679-011-0006-3

Sheehan, B., \& Banerjee, S. (1999). Review: Somatization in the elderly. International Journal of Geriatric Psychiatry, 14(12), 1044-1049.

Smits, J. A., Tart, C. D., Presnell, K., Rosenfield, D., \& Otto, M. W. (2010). Identifying potential barriers to physical activity adherence: Anxiety sensitivity and body mass as predictors of fear during exercise. Cognitive Behavior Therapy, 39(1), 28-36. doi:10.1080/16506070902915261

Spiegel, B. M., Kanwal, F., Naliboff, B., \& Mayer, E. (2005). The impact of somatization on the use of gastrointestinal health-care resources in patients with irritable bowel syndrome. American Journal of Gastroenterology, 100(10), 2262-2273. doi:10.1111/ j.1572-0241.2005.00269.x

Van Oudenhove, L., Vandenberghe, J., Vos, R., Holvoet, L., Demyttenaere, K., \& Tack, J. (2011). Risk factors for impaired health-related quality of life in functional dyspepsia. Alimentary Pharmacology \& Therapeutics, 33(2), 261-274. doi:10.1111/j.1365-2036. 2010.04510.x

van Tilburg, M. A., Palsson, O. S., \& Whitehead, W. E. (2013). Which psychological factors exacerbate irritable bowel syndrome? Development of a comprehensive model. Journal of Psychosomatic Research, 74(6), 486-492. doi:10.1016/j.jpsychores.2013.03.004

Warwick, H. M., \& Salkovskis, P. M. (1990). Hypochondriasis. Behaviour Research and Therapy, 28(2), 105-117. 
Whitehead, W. E., Palsson, O. S., Levy, R. R., Feld, A. D., Turner, M., \& Von Korff, M. (2007). Comorbidity in irritable bowel syndrome. American Journal of Gastroenterology, 102(12), 2767-2776. doi:AJG1540[pii]10.1111/j.1572-0241.2007. 01540.x

Whorwell, P. J., McCallum, M., Creed, F. H., \& Roberts, C. T. (1986). Non-colonic features of irritable bowel syndrome. Gut, 27(1), 37-40.

Xing, J., \& Chen, J. D. (2004). Alterations of gastrointestinal motility in obesity. Obesity Research, 12(11), 1723-1732. doi:10.1038/oby.2004.213

\title{
Correlatos del índice de masa corporal en los pacientes moderados y graves con el síndrome del intestino irritable
}

\begin{abstract}
Resumen
SII es un trastorno gastrointestinal común y potencialmente incapacitante, susceptible a las influencias psicológicas fuertes, especialmente entre los pacientes más graves. Se sabe poco sobre el papel de los factores del estilo de vida (p.ej. obesidad) que influyen en la trayectoria de otras enfermedades crónicas. Este estudio ha examinado la correlación entre la obesidad y los diferentes aspectos de la experiencia de enfermedad en los pacientes más graves con el SII. Nuestra hipótesis fue que el SII se podría correlacionar positivamente con peores resultados de salud, incluyendo síntomas más graves del SII, molestias extraintestinales y angustia emocional. Durante el pretratamiento, en una prueba de comportamiento basada en $\mathrm{NIH}, 448$ pacientes con el SII diagnosticados mediante los criterios de Roma (MEDAD $=41$, $\mathrm{MIMC}=26, \mathrm{~F}=8 \%$ ) fueron sometidos a una batería de prueba que incluía una variedad de variables clínicas (gravedad del SII, miedo de síntomas gastrointestinales, IMC etc.) y sociodemográficas (p. ej. edad etc.) El IMC fue positiva y significativamente correlacionado con la somatización (molestias somáticas inexplicadas), pero no con la gravedad de los síntomas del SII o angustia emocional. Una serie de múltiples análisis regresivos moderados demostró que la relación entre el IMC y la somatización fue moderada por la interacción entre el IMC, la edad y el miedo de los síntomas gastrointestinales. Los pacientes mayores con el IMC más alto mostraron niveles de somatización más altos, y los pacientes que tenían más miedo de los síntomas gastrointestinales tenían más posibilidad de sufrir la somatización si tenían también el IMC alto. Estos datos subrayan la relación entre los factores de estilo de vida y los síntomas extraintestinales entre los pacientes más graves con el SII, tanto como el impacto que tienen factores sociodemográficos (edad) y psicosociales (miedo de los síntomas gastrointestinales) en su relación.
\end{abstract}

Palabras clave: síndrome del intestino irritable, trastorno gastrointestinal, índice de masa corporal, sensibilidad visceral, somatización

Received: January 3, 2018 
